Acta Botanica Mexicana 67: 49-57 (2004)

\title{
NOTAS SOBRE LA FAMILIA BROMELIACEAE EN EL VALLE DE MÉXICO
}

\author{
Adolfo Espejo Serna y Ana Rosa López-Ferrari \\ Herbario Metropolitano, Departamento de Biología, C.B.S., Universidad \\ Autónoma Metropolitana Unidad Iztapalapa, Apartado postal 55-535 \\ 09340 México, D. F. e-mail: aes@xanum.uam.mx
}

\section{RESUMEN}

Se presentan algunas correcciones y actualizaciones nomenclaturales, así como una adición a las Bromeliaceae en la Flora fanerogámica del Valle de México.

Palabras clave: Bromeliaceae, Tillandsia, Valle de México, Viridantha.

\begin{abstract}
Some corrections and nomenclatural changes and one addition to the Bromeliaceae in the Flora fanerogámica del Valle de México are presented.

Key words: Bromeliaceae, Tillandsia, Valle de México, Viridantha.

\section{INTRODUCCIÓN}

Recientemente apareció la segunda edición de la obra Flora fanerogámica del Valle de México (Rzedowski, Rzedowski y cols., 2001), contribución fundamental para el conocimiento de los recursos vegetales de nuestro país y que constituye además la primera obra en su género terminada y actualizada para México. En dicha obra, Victoria (2001) registra para la familia Bromeliaceae la presencia de dos géneros y 18 especies (Apéndice).

Como parte del proyecto Flora Bromeliológica Mexicana, que estamos realizando en colaboración con varios colegas especialistas en la familia, llevamos a cabo una revisión detallada de la literatura relativa a todas las especies mexicanas y detectamos en la susodicha contribución algunos aspectos que deben actualizarse,
\end{abstract}


así como la necesidad de añadir una especie presente en el Valle de México y no considerada previamente.

El objetivo de este trabajo es presentar las modificaciones pertinentes, que a continuación se enlistan.

1. Las plantas identificadas por Victoria (2001) como Tillandsia parryi Baker, corresponden en realidad a Tillandsia sueae Ehlers. Ambas especies son vegetativamente similares y fáciles de confundir, sobre todo en material herborizado. Sin embargo, $T$. parryi tiene flores verdes de antesis nocturna y crece de preferencia como rupícola (Ehlers, 1991; Sill, 2002), en tanto que T. sueae tiene las flores de color violeta de antesis diurna y las plantas son generalmente epífitas, características estas últimas presentes en los ejemplares provenientes del Valle de México.

2. Espejo (2002) propuso la segregación de un grupo de especies tradicionalmente consideradas en Tillandsia, ubicándolas en el nuevo género Viridantha, el cual se diferencia del primero por presentar flores descendentes, con los pétalos ligulados, de 2 a $3 \mathrm{~cm}$ de largo, no constreñidos para formar una garganta, estambres inclusos, todos iguales en longitud, con los filamentos aplanados, las anteras subbasifijas y el estigma del tipo simple erecto (tipo I sensu Brown \& Gilmartin, 1984). Dos de las especies que crecen en el Valle de México, consideradas (Victoria, 2001) como $T$. lepidosepala y $T$. tortilis pertenecen al nuevo género propuesto y el nombre actualizado para dichas especies será entonces: Viridantha lepidosepala (L. B. Sm.) Espejo y Viridantha tortilis (Klotzsch ex Baker) Espejo.

3. Finalmente, es necesario incluir dentro de la flora bromeliológica del Valle a un taxon omitido por Victoria en su contribución, a mencionar Tillandsia alfredolauii Rauh \& Lehm., descrito por Rauh y Lehman (Rauh, 1983), con material proveniente de Carboneras, municipio de Mineral del Chico, Hidalgo, cerca de los límites septentrionales del Valle de México. En dicha localidad crecen simpátricas $T$. violacea Baker y T. erubescens Schltdl., por lo que en nuestra opinión y la de algunos otros especialistas, $T$. alfredo-lauii podría ser un híbrido natural entre ambas especies. Independientemente de lo mencionado arriba, tenemos registros de dicho taxon provenientes de áreas distintas de la localidad tipo, por lo que consideramos importante incluirlo en este trabajo. T. alfredo-lauii se confunde fácilmente con $T$. violacea Baker y con T. prodigiosa (Lem.) Baker, ya que en sendos casos se trata de plantas con rosetas tipo tanque e inflorescencias péndulas, con brácteas rosadas a rojas. Sin embargo, T. violacea presenta flores con los pétalos de color violeta y aunque $T$. alfredo-lauii y $T$. prodigiosa tienen pétalos verdes pálidos, las dos 
especies se distinguen claramente entre sí por las características peculiares de sus inflorescencias y sus rosetas, tal como se señala en la clave anexa.

A continuación proporcionamos una descripción completa de esta especie, así como algunos datos sobre su distribución y preferencias ecológicas.

Tillandsia alfredo-lauii Rauh \& Lehm. (Figs. 1 y 2). Planta acaule de hasta $35 \mathrm{~cm}$ de alto, incluyendo la inflorescencia; hojas numerosas, de hasta $25 \mathrm{~cm}$ de largo, dispuestas en una roseta tipo tanque, vainas oblongo-ovadas, de 5 a $7 \mathrm{~cm}$ de largo por 3 a $3.5 \mathrm{~cm}$ de ancho, de color pardo claro, densamente escamosas; láminas angostamente triangulares, involutas, de 20 a $30 \mathrm{~cm}$ de largo por 1.5 a $3 \mathrm{~cm}$ de ancho en la base, densamente blanco-escamosas, discoloras, el ápice largamente filiforme; escapo recurvado, de ca. $16 \mathrm{~cm}$ de largo, por 3 a $5 \mathrm{~mm}$ de diámetro y sus brácteas erectas a suberectas, foliáceas, imbricadas, de hasta $23 \mathrm{~cm}$ de largo, sobrepasando a la inflorescencia propiamente dicha; inflorescencia péndula, bipinnada, de 13 a $14.5 \mathrm{~cm}$ de largo, con 5 a 7 espigas, adpresas a suberectas, dispuestas en espiral, brácteas primarias ovado-triangulares, largamente acuminadas, esparcidamente escamosas a glabrescentes y rojas por fuera en la porción basal, densamente escamosas y verdes hacia el ápice, de 11.5 a $19.5 \mathrm{~cm}$ de largo por ca. $3 \mathrm{~cm}$ de ancho en la parte media, espigas de 4 a $6 \mathrm{~cm}$ de largo por $2 \mathrm{~cm}$ de ancho, las basales con cerca de tres flores, las apicales con dos, brácteas florales erectas, imbricadas, esparcidamente escamosas, ecarinadas, mucronadas, de color rosado a rojo hacia el ápice y verdes hacia la base, de 3.5 a $4.5 \mathrm{~cm}$ de largo por ca. $2 \mathrm{~cm}$ de ancho, membranáceas; sépalos libres, elípticos, acuminados, membranáceos, de 2.5 a $3 \mathrm{~cm}$ de largo por 8 a $10 \mathrm{~mm}$ de ancho, blanco-verdosos, los posteriores carinados; pétalos oblongoespatulados, de color verde muy pálido, de 5 a $6 \mathrm{~cm}$ de largo por 7 a $8 \mathrm{~mm}$ de ancho, recurvados en el ápice; estambres exertos, los filamentos desiguales, blancos, de 6.2 a $7.2 \mathrm{~cm}$ de largo, anteras oblongas, amarillas, de ca. $4 \mathrm{~mm}$ de largo; ovario largamente ovoide, verde, de ca. $1 \mathrm{~cm}$ de largo por ca. $3 \mathrm{~mm}$ de diámetro; estilo blanco, de ca. $7 \mathrm{~cm}$ de largo. Fruto una cápsula verde, alargada. Planta endémica del estado de Hidalgo, en donde se localiza en los municipios de Mineral del Chico y Mineral del Monte. Alt. 2000-2700 m. Epífita en bosques de encino y/o de pinoencino-oyamel.

Ejemplares examinados: Valle de México: municipio de Mineral del Monte, Peñas Cargadas, cerca de Real del Monte, 5.III.1977, R. Hernández M. $3036 a$ (MEXU). Otras localidades cercanas al área de estudio: municipio de Mineral del Chico, alrededores de Carboneras, 20¹4' N; 99¹6' W, ca. 2000 m, IV.2002, A. Espejo y J. Espejo 6372 (UAMIZ); municipio de Mineral del Chico, Carboneras, ca. 2000 m, VI.1981, A. Lau Jr. s. n. (HEID). 
Acta Botanica Mexicana 67: 49-57 (2004)

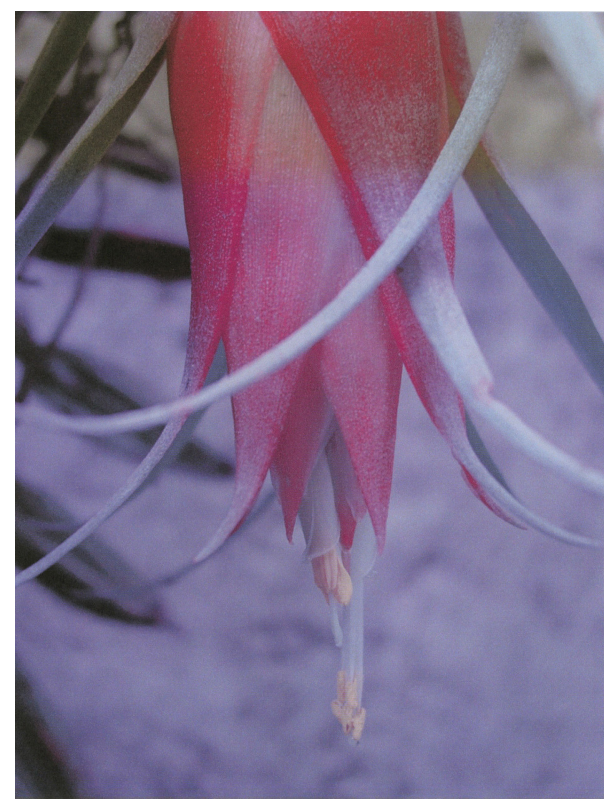

Fig. 1. Tillandsia alfredo-lauii Rauh \& Lehm. Detalle de la inflorescencia. (del ejemplar $A$. Espejo y J. Espejo 6372 (UAMIZ)).

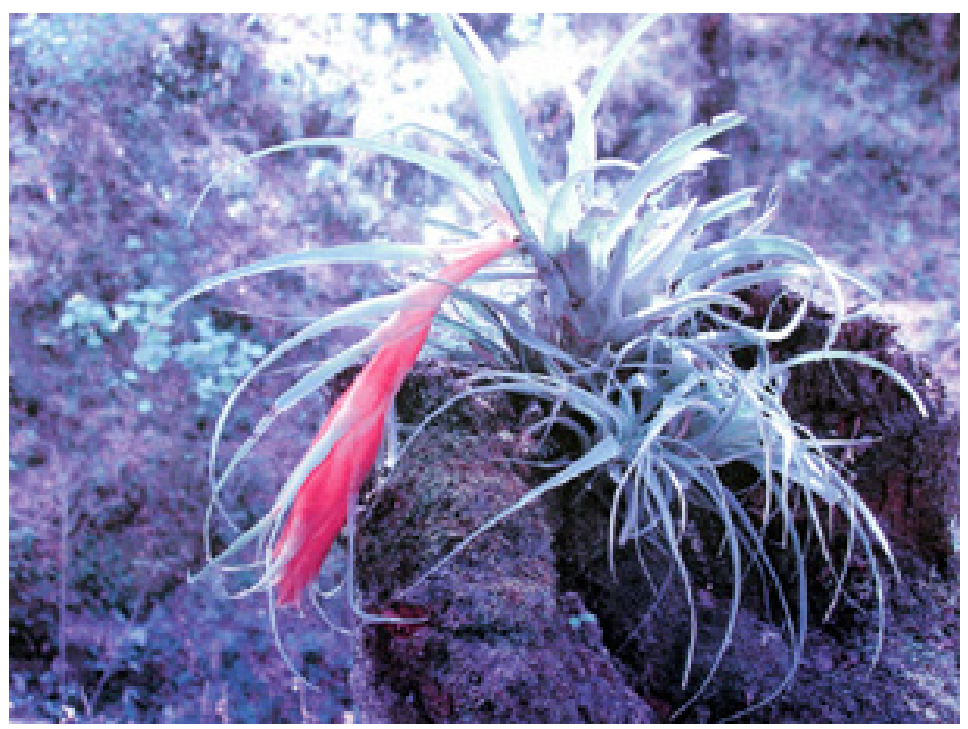

Fig. 2. Tillandsia alfredo-lauii Rauh \& Lehm. Hábito. (del ejemplar A. Espejo y J. Espejo 6372 (UAMIZ)). 
Como resultado de los cambios arriba propuestos es necesario adecuar las claves de identificación.

Clave para los géneros (adaptada de Victoria, 2001)

1. Hojas con el borde espinoso-serrado; flores unisexuales, con los dos sexos presentes pero uno de ellos no funcional; semillas algo aladas; plantas terrestres Hechtia

1. Hojas con el borde entero; flores hermafroditas; semillas plumosas; plantas por lo general epífitas, a veces rupícolas.

2. Plantas largamente caulescentes, colgantes; pétalos fuertemente reflexos, de $1 \mathrm{~cm}$ o menos de largo .................. Tillandsia (Diaphorantema) usneoides

2. Plantas arrosetadas a muy cortamente caulescentes; pétalos no reflexos a ligeramente recurvados en el ápice, generalmente de más de $2 \mathrm{~cm}$ de largo (de ca. $1 \mathrm{~cm}$ en $T$. recurvata).

3. Estambres inclusos; flores de color verde oscuro, con los pétalos ligulados, no constreñidos para formar una garganta; plantas con tendencia a la caulescencia Viridantha

3. Estambres exertos; flores de color morado, azul o verde claro, con los pétalos espatulados y constreñidos formando una garganta; plantas arrosetadas, nunca caulescentes Tillandsia

Clave para las especies del género Viridantha (adaptada de Espejo, 2002)

1. Escapo linear, de más de $6 \mathrm{~cm}$ de largo y de ca. $1 \mathrm{~mm}$ de diámetro; pétalos de 25 a $28 \mathrm{~mm}$ de largo $V$. tortilis

1. Escapo ausente o de estar presente, siempre menor de $1 \mathrm{~cm}$ de largo y de ca. 2-3 $\mathrm{mm}$ de diámetro; pétalos de 21 a $23 \mathrm{~mm}$ de largo V. lepidosepala

Clave para las especies del género Tillandsia (adaptada de Victoria, 2001)

1. Hojas en posición dística, hasta de $2 \mathrm{~mm}$ de diámetro; inflorescencia con 1 a 5 flores.

2. Tallo no mayor de $10 \mathrm{~cm}$ de largo; plantas agrupadas en masas más o menos esféricas, con raíz fibrosa; escapo manifiesto, inflorescencia terminal, con 1 (2 a 5) flores; pétalos violáceos T. recurvata

2. Tallo colgante, hasta de varios metros de largo, sin raíz; escapo ausente; inflorescencia pseudolateral, con una sola flor; pétalos verdes ..... T. usneoides 
1. Hojas en posición polística, por lo general de más de $2 \mathrm{~mm}$ de ancho o diámetro; inflorescencia por lo común con 3 o más flores.

3. Vainas de las hojas infladas, convergentes cerca de sus ápices, formando un pseudobulbo basal; plantas escasísimas en el Valle de México, que no se han colectado en los últimos 80 años.

4. Láminas de las hojas de más de $5 \mathrm{~mm}$ de ancho en la base, sus vainas verdosas, de color uniforme; brácteas florales glabras o casi glabras ......

T. caput-medusae

4. Láminas de las hojas de menos de $5 \mathrm{~mm}$ de ancho en la base, sus vainas variegadas; brácteas florales densamente escamosas T. butzii

3. Vainas de las hojas extendidas, sin formar un pseudobulbo basal, aunque a veces estén algo infladas.

5. Flores en posición polística, dando aspecto cilíndrico a la inflorescencia, ésta por lo general en forma de espiga simple.

6. Sépalos densamente escamosos, ampliamente oblanceolados; pétalos de color violeta T. macdougallii

6. Sépalos glabros o esparcidamente escamosos, lanceolados.

7. Pétalos de color verde pálido; brácteas florales agudas; láminas de las hojas involuto-subuladas sólo en el ápice. T. erubescens

7. Pétalos de color violeta; brácteas florales obtusas o apiculadas; láminas de las hojas involuto-subuladas por lo menos en un tercio de su longitud T. andrieuxii

5. Flores en posición dística, dando aspecto aplanado a la inflorescencia o a sus ramas.

8. Lámina de la hoja linear-subulada, de $1 \mathrm{~cm}$ o menos de ancho en la base T. juncea

8. Lámina de la hoja triangular, con el ápice atenuado, de $2 \mathrm{~cm}$ o más de ancho en la base.

9. Espigas angostamente oblongas o linear-lanceoladas, 4 o más veces más largas que anchas, fuertemente comprimidas; escapo erecto.

10. Brácteas primarias inferiores tan largas o más largas que las espigas, éstas oblongas, laxas, de modo que el raquis queda expuesto. T. sueae

10. Brácteas primarias inferiores evidentemente más cortas que las espigas, éstas linear-lanceoladas, densas, de modo que el raquis queda oculto por las brácteas florales. T. dugesii

9. Espigas ovadas a ampliamente lanceoladas, menos de 4 veces más largas que anchas.

11. Escapo erecto; pétalos de color verde; brácteas florales escamosas, al menos en el margen. 
Espejo y López-Ferrari.: Bromeliaceae en el Valle de México

12. Sépalos densamente escamosos; espigas erectas, sésiles ... T. bourgaei

12. Sépalos glabros o con algunas escamas grandes; espigas divergentes hasta en $45^{\circ}$, todas o al menos las inferiores pedunculadas ......................................................... T. cossonii

11. Escapo recurvado, la inflorescencia péndula.

13. Pétalos de color violeta; espigas perpendiculares a la bráctea primaria; las inferiores con un pedúnculo robusto evidente, de hasta $1.5 \mathrm{~cm}$ de largo T. violacea

13. Pétalos de color verde pálido; espigas paralelas a la bráctea primaria; el pedúnculo nunca de más de $5 \mathrm{~mm}$ de largo.

14. Plantas robustas, con inflorescencias de hasta $70 \mathrm{~cm}$ de largo, nunca sobrepasadas por las brácteas del escapo y con el raquis expuesto; espigas de 5 a $9 \mathrm{~cm}$ de largo, con 10 a 12 flores; brácteas florales y sépalos coriáceos T. prodigiosa

14. Plantas de talla mediana, con inflorescencias nunca mayores de $30 \mathrm{~cm}$ de largo, sobrepasadas por las brácteas del escapo y con el raquis cubierto por las brácteas primarias; espigas de 4 a $6 \mathrm{~cm}$ de largo, con 2 a 3 flores; brácteas florales y sépalos membranáceos.... T. alfredo-lauii

\section{AGRADECIMIENTOS}

Queremos manifestar nuestro agradecimiento a los DD. Graciela Calderón de Rzedowski, Jerzy Rzedowski R. e Ivón Ramírez M. por sus observaciones y comentarios al manuscrito. A los curadores de los herbarios revisados reconocemos las facilidades otorgadas. Las fotografías fueron tomadas por Adolfo Espejo.

\section{LITERATURA CITADA}

Brown, G. K. \& A. J. Gilmartin. 1984. Stigma structure and variation in Bromeliaceae neglected taxonomic characters. Brittonia 36(4): 364-374.

Ehlers, R. 1991. A new Tillandsia species: Tillandsia sueae. J. Bromeliad Soc. 41(5): 208213, figs. 6-11.

Espejo, A. 2002. Viridantha, un género nuevo de Bromeliaceae (Tillandsioideae) endémico de México. Acta Bot. Mex 60: 25-35. 
Rauh, W. 1983. Bromelienstudien. I. Neue und wenig bekannte Arten aus Peru und anderen Ländern. Akad. Wiss. Abh. Math.-Naturwiis. Kl. Trop. Subtrop. Pflanzenwelt 41: 132.

Rzedowski, G. C de, J. Rzedowski y colaboradores. 2001. Flora fanerogámica del Valle de México, 2a. ed., Instituto de Ecología A. C. y Comisión Nacional para el Conocimiento y Uso de la Biodiversidad. Pátzcuaro, Michoacán. 1406 pp.

Sill (Gardner), S. 2002. Tillandsia parryi and Tillandsia sueae, sister species of central Mexico. J. Bromeliad Soc. 52(4): 147-151, figs. 1-5.

Victoria H., A. 2001. Bromeliaceae In: Rzedowski, G. C de, J. Rzedowski y colaboradores. Flora fanerogámica del Valle de México, 2a. ed., Instituto de Ecología A. C. y Comisión Nacional para el Conocimiento y Uso de la Biodiversidad. Pátzcuaro (Michoacán). pp. 1179-1187.

Recibido en mayo de 2003. Aceptado en marzo de 2004. 
Espejo y López-Ferrari.: Bromeliaceae en el Valle de México

Apéndice. Taxa de Bromeliaceae presentes en el Valle de México.

\begin{tabular}{|c|c|}
\hline Victoria (2001) & Espejo y López-Ferrari (en este trabajo) \\
\hline Hechtia podantha Mez & Hechtia podantha $\mathrm{Mez}$ \\
\hline Hechtia stenopetala Klotzsch & Hechtia stenopetala Klotzsch \\
\hline 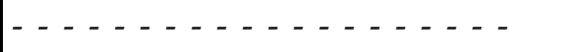 & Tillandsia alfredo-lauii Rauh \& Lehm. \\
\hline Tillandsia andrieuxii (Mez) L. B. Sm. & Tillandsia andrieuxii (Mez) L. B. Sm. \\
\hline Tillandsia bourgaei Baker & Tillandsia bourgaei Baker \\
\hline Tillandsia butzii Mez & Tillandsia butzii Mez \\
\hline Tillandsia caput-medusae E. Morren & Tillandsia caput-medusae E. Morren \\
\hline Tillandsia cossonii Baker & Tillandsia cossonii Baker \\
\hline Tillandsia dugesii Baker & Tillandsia dugesii Baker \\
\hline Tillandsia erubescens Schltdl. & Tillandsia erubescens Schltdl. \\
\hline Tillandsia juncea (Ruiz \& Pav.) Poir. & Tillandsia juncea (Ruiz \& Pav.) Poir. \\
\hline Tillandsia lepidosepala L. B. Sm. & $\begin{array}{l}\text { Viridantha lepidosepala (L. B. Sm.) } \\
\text { Espejo }\end{array}$ \\
\hline Tillandsia macdougallii L. B. Sm. & Tillandsia macdougallii L. B. Sm. \\
\hline Tillandsia parryi Baker & Tillandsia sueae Ehlers \\
\hline Tillandsia prodigiosa (Lem.) Baker & Tillandsia prodigiosa (Lem.) Baker \\
\hline Tillandsia recurvata (L.) L. & Tillandsia recurvata (L.) L. \\
\hline Tillandsia tortilis Klotzsch ex Baker & $\begin{array}{l}\text { Viridantha tortilis (Klotzsch ex Baker) } \\
\text { Espejo }\end{array}$ \\
\hline Tillandsia usneoides (L.) L. & Tillandsia usneoides (L.) L. \\
\hline Tillandsia violacea Baker & Tillandsia violacea Baker \\
\hline
\end{tabular}

